\title{
Studying and Analyzing the Brand Social Power Bases in the Iranian Auto-Making Industry (Case Study: Iran khodro)
}

\author{
Ali Shariat nejad \\ MA Student of Business Management, Lorestan University, Khorram Abad, Iran \\ Mehrdad Naserpour \\ MA Student of Business Management, Lorestan University, Khorram Abad, Iran \\ Mohammad Veysi \\ MA Student of Business Management, Lorestan University, Khorram Abad, Iran \\ Ali Sereshoumi* \\ MA Student of Business Management, Lorestan University, Khorram Abad, Iran \\ *Corresponding Author_Email: alisereshoumi_mm@yahoo.com
}

Doi:10.5901/mjss.2016.v7n3s3p231

\section{Abstract}

The main purpose of the present research is to analyze and study bases of brands'social power in the auto-making industry as well as to provide an applied solution to increase the power of brands' social bases in this industry. This study in the terms of purpose is an applied research and in the terms of collecting the data and information is a descriptive research. As for the statistic population it should be noted that the statistic population of the research is composed of the staff in permitted agencies of Iran Khodros' Company in Khorram-Abad. Using the Morgan table, the sample volume of 48 persons was obtained and by the means of stratified-random sampling method, the questionnaires were distributed among them. To evaluate the variables of the brands's social power, a researcher-made questionnaire was extracted from the standard questionnaires covering the research items. It is worth noting that validity of the present questionnaire was confirmed using content validity method, and reliability of the questionnaire was ratified by the means of SPSS software cronbach's alpha test. To study the research hypotheses, the factor analysis procedure along with Amos 18 software is used. Research results indicate that the IranKhodro's brand does not have the ability to affect the customer's behavior through coercive power or reward power. Moreover, the research results show that the Iran Khodro's brand can affect the customer's behavior using its legitimacy along with the brand referent social power and expert social brand.

Keywords: the brand's social power, coercive brand social power, reward brand social power, legitimate brand social power, referent brand social power, expert brand social power

\section{Introduction}

Today, due to the limitation of energies and sources, we can see an increase competition between companies which leads to the advent of organizations in the competitive market so that they inevitably use the tangible and intangible assets efficiently. Therefore, the role of intangible assets on the activities and improving the business performance in different industries has been increased (Hassani et al, 2013). One the most important intangible assets for each organization is the brand. A brand can be powerful when it can influence the image of the consumers and it also can affect the normal preferences, tendencies, and purchased behavior for that brand as routine. Today, a brand is an integral part of the marketing strategy; bran marketing is at the center of business (Mmaeni \& Shahrokhi, 1998). Most of well known country in the world like Procter, Gamble, \& Mars are structured around their brand (Baker et al, 2002). Hence, due to the importance of brand in competitive markets, a brand is powerful that can affects customer's behavior for purchase. Then, a question which the present research seeks to answer is that, how are the brand's social powers bases in the Iranian auto-making industry?

Due to the high-fast changes in the world and fading the economical borders, in order to maintain the Iranian 
companies to compete with foreign companies and having a powerful presence in the internal markets as well as increasing the power of export, making a valid and powerful brand is inevitable. The worldwide changes in auto-industry with the presence of the companies with powerful brands will be a warning for the independent companies of the area like Iran so that it can make itself ready faces the coming wave of changes that can be a tsunami; otherwise, it should leave this field and let other companies go ahead. The major solution to maintain and compete with reputed companies in automaking industry is the ability to affect on the customer buying behavior. This is achievable by a powerful brand (Chahdhuri \& Halbrook, 2001). The consumers attribute the value of a product to its brand. When a bran can have a powerful status in the customer minds, it can assure the costumers to have it and this makes the consumers not to change their purchase behavior from brand to brand (Chen,2007). Therefore, according to above mentioned, the present research aims to study the brand's social power in the auto-making industry and present an applied solution increase the power of the brand's social bases.

\section{Literature Review}

\subsection{The brand power}

According to the definition of American marketing association (AMA), a brand is a name, term, sign, logo, design or a mix of all of these which aim to identify the items or services of a seller or a group of sellers and differentiate these items and services from their competitors. In other words a brand is part of a commercial logo which is utterable meaning that we can pronounce it (Cutler \& Armstrong, 2005). The concept of power in general and according to the typology of French \& Rion (1959) has been used in many different fields of marketing (Heidar-Zadeh et al, 2010). The brand power is variable with a relatively wide definition studying the marketing strategies and customer's perception from the company's products in a dynamic interaction (chyrany \& Sabouri, 2011). A brand can convey a positive or negative image to the customers about the products. In such a case, powerful naming, it accelerates the awareness and acceptance of the market towards the products coming into the market (Joseph, 1995); customers attribute the value of a product to its brand. When a bran can have a powerful status in the customer minds, it can assure the costumers to have it and this makes the consumers not to change their purchase behavior from brand to brand (Chen,2007). In another definition, the brand power means the presence of a brand in the consumers mind, and how the consumers can remember it as fast as possible. Most experts believe that a condition needed to make a powerfully brand is to put a good remembering in the consumer's mind (Bong na et al, 1999).

\subsection{Brand social power}

The success of most brands in the market is dependent on of the customer's image from the power of that brand (Hughes \& Ahearn, 2010). Hence, in order to be successful in the market, we should have powerful brand in the market. One of the models to create a more powerful brand is customer-centric model of brand equity. According to this model is how the consumers feel about the brand over time? And what they learn? The brand power is how long it can remain in the consumer's minds (Keller, 2011).

By the expansion of the general definition of power to the conditions for creating a brand the brand social power is considered as part of customer-centric power of brand equity; irrespective of considering this concept naturally cognitive or communicative the more social power is for bran, the more customer-centric power of brand equity will have (HeidarZadeh et al, 2010). In fact the brand social power is common set and five-dimension of social factors and marketing affecting the perception, values, and customer's behavior (Heidar-Zadeh \& Ghalandari, 2010). The major bases of the theory for brand social power are the krosno, Ferling, and Skinner's researches. Conducted by the primary research of French and Roin based on the above mentioned researches the major dimensions of the brand social power consist of five parts (Krosno et al, 2009). Therefore, the major dimensions of the brand social power can be divide into coercive brand social power, reward brand social power, legitimate brand social power, referent brand social power and expert brand social power (Heidar-Zadeh, Ghalandari, 2011).referent brand social power and expert brand social power (HeidarZadeh, Ghalandari, 2011).

\subsection{The Dimensions of Brand Social Power}

In the present research and based on the theory of brad social power of Kronso, Ferling and Skinner (2009), the base of brand social power includes five parts. Therefore, the major dimensions of brand social power can be divided into 
coercive brand social power, reward brand social power, legitimate brand social power, referent brand social power and expert brand social power.

The coercive brand social power: the coercive brand social power emphasizes on the brand ability affecting the consumer's behavior through creating awareness towards negative outcomes such as dissatisfaction, sense of failure, sense of being outsider, or lack of being confirmed and the inferior impressed social status while not using the brand. The rate of coercive brand social power has direct relationship with this fact that customers attribute the negative outcome to the lack of using the brand of a company, and they have a strong tendency to avoid the punishment related to the lack of use of company's brand (Hersy \& Blanchard 2007, as quoted by Heidar-Zadeh et al).

The reward brand social power: the reward brand social power emphasizes on the ability of brand affecting on the customer's behavior through the impression that the brand can bring about positive outcome. The positive outcome refers to inherent rewards that a brand can provide with the customers such as satisfaction, sense of success, sense of acceptability, superior impressed social status (Kronso et al, 2009, as quoted by Heidar-Zadeh et al).

The legitimate brand social power: it emphasizes on the ability of brand affecting the customer's behavior through stock market, reputation, and industry background. The most powerful legitimate brand social power is its reputation. Vergin and Chron-Fillet (1998) conducted a functional analysis of stocks and reputation of the company showing that the brand performance of a company has a positive and direct relationship with its reputation. The reason that the reputation of a company leads to a better function of the market is the consumers purchase to the items and service of the company and its new products (Vergin \& Chron- Fellit, 1998, as quoted Heidar-Zadeh Honzaee \& Qalandari). Referent brand social power: it emphasizes on the ability of a brand affecting the consumer's behavior by reinforcing the brand' $s$ attraction or the sense of closeness to the brand due to its uniqueness. When a brand has a high referent brand social power, the consumers have the sense of the uniqueness and seek to have a close relationship with this brand (Heidarzadeh Honzaee, Qalandari, 2011).

Expert brand social power: the importance of measuring the organizational performance has been considered from different aspects and according to common various levels in marketing literature as a crucial variable. Therefore, there is an attitude to evaluate the performance through the products and services provided by the organization which is so called as the brand performance (Chirani et al, 2012). The brand performance means the brand ability affecting the consumer's behavior through creating these impressions bring about expertise, specialize knowledge, innovativeness, quality, superior continuous performance, and higher knowledge for individuals (Kronso et al,2009).

\section{Research Background}

As for the research background it should be noted that according to the research review, there has just been conducted one research inside the country, this research conducted by Heidar-Zadeh et al (2010), brand social power is considered as an image that costumers can have about the brand qualities in the process of decision-making; five powerful social bases of brand were identified by selection of French and Rion (1959) topology from social influence. On the other hand, supposing that the brands have the power to meet the different social needs of the customers, markets can be divided; the purpose sections can be identified based on these needs. By the virtue of the leadership of Hersy and Blanchard, the staff preparation level was generalized to the mental preparation level to provide a new index to sectionalize market. Finally, the research results show that the effect of brand social power dimension is different on the different levels of costumer's image preparation to make decision to purchase. As for the present research background it should be noted that in a research conducted by Kronso et al (2009), the researches related to creating a brand has been mixed with the social influence theory so that it can define the brand social power and codify a topology of brand social power. The results of this research show that the power of a brand is based on the impression qualities a consumer makes from a brand not the inherent or certain features; like any other connection with a brand, it can help the consumer in marketing and processing the related data to create a brand, differentiate a brand, select a brand, etc. in another research conducted by Heidar-Zadeh Hamzaee and Qalandari (2011), the effect of brand social power on the customer's purchase decision is evaluated. The results indicate that the brand social power knowledge can be considered to differentiate a brand from its competitors; on the other hand the preparation levels of customer's images plays a crucial rule effecting the brand social power to attitudes, emotions, arguments of customers to purchase a brand so that it can help the brand management process to determine the position strategies in target markets.

\section{Research Conceptual Framework}

In the present research in order to analyze the brand social power status, for each dimension of this concept, some 
elements are defined according to the literature review. To codify the research model, to models have been used. In this way the model of Heidar-Zadeh, Alvani and Qalanderi (2010) has been used. The two mentioned models, consider the brand social power bases as five dimensions depicted in figure one.

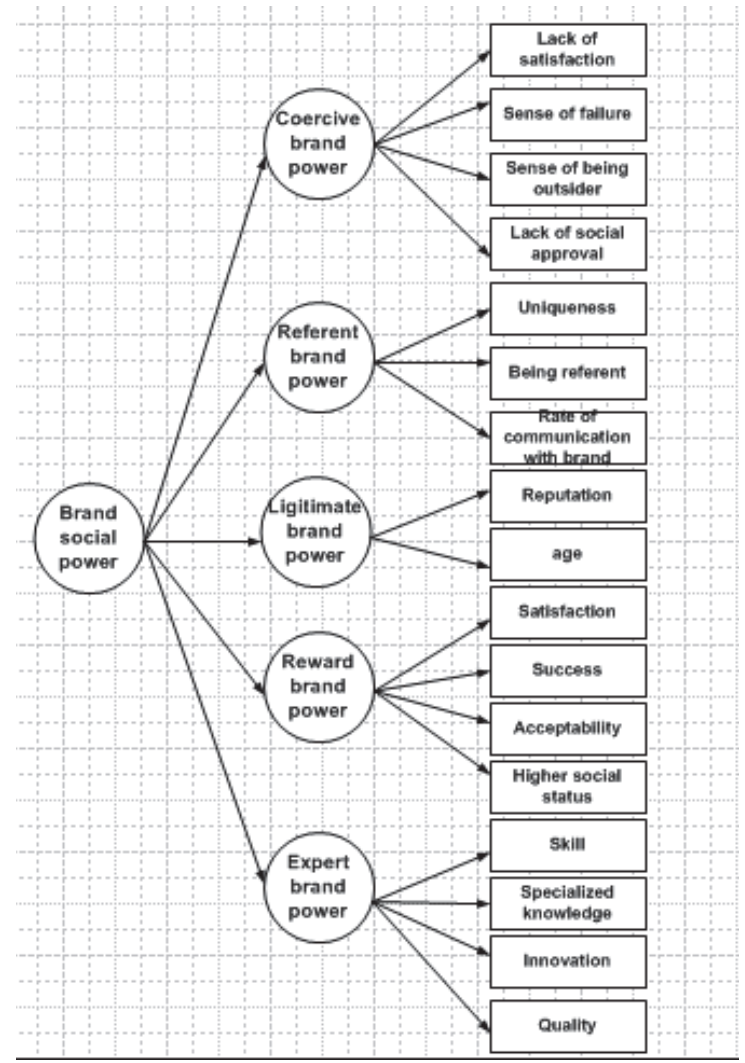

Figure one: Conceptual framework

\section{Research Hypothesis}

- Coercive brand power is a positive index to increase the brand power of Iran-Khodro

- Referent brand power is a positive index to increase the brand power of Iran-Khodro

- Legitimate brand power is a positive index to increase the brand power of Iran-Khodro

- Reward brand power is a positive index to increase the brand power of Iran-Khodro

- Expert brand power is a positive index to increase the brand power of Iran-Khodro

\section{Research Method}

T main purpose of this research is to analyze and study the brand social power status in the auto-making industry as well as to provide an applied solution to increase the power of brands'social bases in this industry. This study in the terms of purpose is an applied research and in the terms of collecting the data and information is a descriptive research. As for the statistic population it should be noted that the statistic population of the research is composed of the staff of permitted agencies of Iran Khodros' Company in Khorram-Abad. Using the Morgan table, the sample volume of 48 persons was obtained and by the means of stratified-random sampling method, the questionnaires were distributed among them. As for the sampling method of the research, it is noted that the agencies in Khorram-Abad were divided into five parts. Then 
based on the size of each part, the questionnaires were distributed among their staff. In table 1, the full-description of sampling is depicted.

Table. 1. sampling quality

\begin{tabular}{cccccc}
\hline row & Agency number & Sales managers & Marketing managers & Ordering department & Sales department \\
\hline 1 & Agency No.1 & 1 & 1 & 3 & 4 \\
2 & Agency No.2 & - & 1 & 5 & 4 \\
3 & Agency No.3 & 1 & - & 3 & 5 \\
$\mathbf{4}$ & Agency No.4 & 1 & 1 & 4 & 4 \\
$\mathbf{5}$ & Agency No.5 & 1 & 1 & 3 & 5 \\
\hline
\end{tabular}

In this research, at first using the library references, the literature review was studied. Then the research variables were measured through a 51- question questionnaire with Lickrit Five option. To assess the variables of the brand social power bases, a research-made questionnaire was extracted from the standard questionnaire covering the research items. It is worth noting that validity of the present research was confirmed using the content-validity method. The research questionnaire was analyzed through SPSS software and Chronbac-Alpha test. The test results of the items show the highly desired stability. In table 2, the questionnaire stability has been depicted by the division of research items.

Table. 2. questionaire reliability

\begin{tabular}{lc}
\hline Variable & Reliability \\
\hline Coercive brand power & 0.73 \\
Referent brand power & 0.77 \\
Legitimate brand power & 0.81 \\
Reward brand power & 0.79 \\
Expert brand power & 0.73 \\
\hline
\end{tabular}

\section{The Descriptive Findings of Research}

In this research, the descriptive results of the research include the analysis the sampling demography and KMO coefficient. By studying the related data to the sex, it will be clear that 20 persons equaled as 0.42 are female and 28 persons equaled as 0.58 are male. Also, among the selected sample, 18 persons are less than 30 years old equaled as 0.38 of the selected sampling size. On the other hand, 20 persons are between ages of 31-40 constituting 0.42 of the sampling size. The sampling members higher than 41 years old are 10 persons constituting 0.21 of the sampling size. As for the KMO coefficient, it should be noted that the numerical value of $\mathrm{KMO}$ is higher than 0.7 showing the desirability coefficient use of the factor analysis.

\section{Research Methodology}

In this research, to analyze the questions in the questionnaire and hypothesis test, we used confirmatory factor analysis. Factor analysis is a technique making possible the reduction of lots of the dependant variables into a smaller number of covert or overt factors. The main goal of this factor analysis is to summarize data. This method deals with the internal corelationship of a great number of variables. Finally, they are categorized as limited general factors. Therefore, the factor analysis value is that it provides with a useful analysis so that it can be interpreted a great deal of behavior with the highest saving in the determined structures. Hence, the present research aims to deal with to analyze the five-dimension bases of brand social power in the auto-making industry. Therefore, in the present research, the information of all factors (five-dimension bases of brand social power) has been gathered using the questionnaire; then, the power size of each factor in the auto-making industry is dealt with by Amos software.

\section{Research Findings}

In this research, we study the item validity of the research tools by reviewing the research literature and using confirmatory analysis factor. The overall results are depicted in table. 3. 
Table. 3. factor analysis of brand social power dimensions

\begin{tabular}{|l|l|c|c|c|}
\hline variable & Dimensions & Factor loads & Crisis rate & P \\
\hline \multirow{4}{*}{ Coercive brand power } & Dissatisfaction & 0.45 & 3.11 & 0.000 \\
\cline { 2 - 5 } & Sense of being outsider & 0.28 & 1.47 & 0.075 \\
\cline { 2 - 5 } & Sense of failure & 0.21 & 1.36 & 0.086 \\
\cline { 2 - 5 } & Lack of social approval & 0.24 & 1.39 & 0.092 \\
\hline \multirow{3}{*}{ Referent brand power } & Brand uniqueness & 0.48 & 3.19 & 0.000 \\
\cline { 2 - 5 } & Being a model & 0.42 & 3.04 & 0.000 \\
\cline { 2 - 5 } & Interest related to brand & 0.40 & 3.01 & 0.000 \\
\hline \multirow{3}{*}{ Regitimate brand power } & reputation & 0.51 & 3.28 & 0.000 \\
\cline { 2 - 5 } & age & 0.55 & 3.45 & 0.000 \\
\hline \multirow{5}{*}{ Expert brand power } & Satisfaction & 0.41 & 2.58 & 0.008 \\
\cline { 2 - 5 } & Success & 0.40 & 2.42 & 0.011 \\
\cline { 2 - 5 } & Acceptability & 0.32 & 1.60 & 0.093 \\
\cline { 2 - 5 } & Higher social status & 0.18 & 1.02 & 0.212 \\
\hline & Expertise & 0.43 & 2.55 & 0.000 \\
\cline { 2 - 5 } & Specialized knowledge & 0.41 & 2.39 & 0.008 \\
\cline { 2 - 5 } & Innovation & 0.34 & 1.69 & 0.097 \\
\cline { 2 - 5 } & Quality & 0.42 & 2.43 & 0.061 \\
\hline
\end{tabular}

According to the factor analysis results, we can notice that only for each of the five-dimension of brand social powers the factor of customer's satisfaction has a desirable factor load level for the coercive brand power. The factor analysis results for the referent brand power show that every three dimensions of this variable are identified as the effective factors on the brand referent power of Iran-Khodro by the applicants. As for the legitimate brand power and its dimensions, it is worth noting that the dimension of this variable have a highly desirable level; and the two factors of reputation and age are the factors making the Iran-Khodro brand legitimate. The factor analyses results for the reward brand power indicate that the two dimensions of this variable have a relatively low factor load level; and the two dimensions of satisfaction and success are the dimensions effecting on the reward brand of Iran-Khodro. Finally the variable of expert brand power was studied in which the variable in the terms of factor load has a relatively desirable level; the results of this analyses show the desirability of the expertise level, specialized knowledge and the quality of Iran-Khodro's products, but based on the applicants views, Iran-Khodro has a low level in the terms of brand innovation.

\section{Research Hypotheses Test}

To test the research hypotheses, we used the confirmatory factor analysis and AMOS 18 software. The factor analysis results were analyzed and studied for the five-dimension bases of brand social power. The full description is depicted on tabl. 4.

Table 4. Factor analysis results of five-dimension bases of brand social power

\begin{tabular}{lccc}
\hline variable & Factor loads & Crises rate & P \\
\hline Coercive brand power & 0.31 & 1.64 & 0.079 \\
Referent brand power & 0.43 & 2.89 & 0.000 \\
Legitimate brand power & 0.53 & 3.27 & 0.000 \\
Reward brand power & 0.33 & 1.82 & 0.084 \\
Expert brand power & 0.40 & 2.31 & 0.000 \\
\hline
\end{tabular}

Based on table (4), all the major research hypotheses except the hypothesis related to coercive brand power and reward brand power were confirmed at the reliability level of 0.95 in the description of the major hypotheses test, it should be mentioned that according to the crises rate (CR), more than 1.96 for the hypotheses related to the research variables with the rate of $(P)$ less than error level of 0.05 , was confirmed at the reliability level of 0.95 . As for the hypotheses related to the coercive brand power and reward brand power, it should be noted that the crisis rate (CR) IS less than 1.96 and $(P)$ is more than the error level of 0.05 . Therefore, based on the table (4) we can have that the related to the hypotheses coercive and reward brand powers are rejected. The full description of the hypotheses along with the conclusion is 
depicted in table five.

Table 5. Research Hypotheses

\begin{tabular}{clc}
\hline Row & Hypotheses & result \\
\hline $\mathbf{1}$ & Coercive brand power is a positive index to increase the brand power of IranKhodro & rejected \\
$\mathbf{2}$ & Referent brand power is a positive index to increase the brand power of IranKhodro & confirmed \\
$\mathbf{3}$ & Legitimate brand power is a positive index to increase the brand power of IranKhodro & confirmed \\
$\mathbf{4}$ & Reward brand power is a positive index to increase the brand power of IranKhodro & rejected \\
$\mathbf{5}$ & Expert brand power is a positive index to increase the brand power of IranKhodro & confirmed \\
\hline
\end{tabular}

According to the research findings it can be noted that Iran-Khodro's does not have any effect on the consumer's behavior through creating awareness towards negative outcomes such as inferior image of sense of failure, sense of being outsider or lack of approval and social status in case of not using the brand. Moreover, the findings show that IranKhodro's brand can effect on the consumer's behavior through images based on the fact that bran can cause positive outcomes such as satisfaction, sense of success, and acceptability. On the other hand, based ha the confirmation of the third hypotheses it can be express that Iran-Khodro's brand can affect the consumer's behavior through reputation and age, consequently leading to legitimate brand power of Iran-Khodro. As for the rejection of the force hypotheses, it should be uttered that Iran-Khodro's brand in the terms of applicants' view is not rewarding; because the result show that this brand does not have a high acceptability and does not create a distinguished social status. Finally, the confirmation of the fifth hypotheses indicates that the appropriate expert brand power of Iran-Khodro can affect the consumer's behavior through images resulted from expertise and or specialized knowledge, quality, and high performance continuity and superior knowledge of the mentioned brand.

\section{Conclusion}

Due to the high-fast changes in the world and fading the economical borders, in order to maintain the Iranian companies to compete with foreign companies and having a powerful presence in the internal markets as well as increasing the power of export, making a valid and powerful brand is inevitable. The worldwide changes in auto-industry with the presence of the companies with powerful brands will be a warning for the independent companies of the area like Iran so that it can make itself ready to face the coming wave of changes that can be a tsunami; otherwise, it should leave this field and let other companies go ahead. Therefore, the main purpose of the present research is that to analyze the brand' s social power in the auto-making industry and present an applied solution increase the power of the brand's social bases. The results of the present research show that Iran-Khodro's brand can not affect the consumer's behavior through creating awareness towards negative outcome such as sense of failure, sense of being outsider, or lack of disapproval and inferior images of social status in case of not using the brand. The reason is that the calculated factor loads for the mentioned dimensions have an undesirable level. The results of the second hypothesis indicates that Iran-Khodro's brand can influence the consumer's behavior through images based on the fact that the brand can cause positive outcomes such as satisfaction, sense of success, and sense of acceptability. Since the results of factor loads are in a desirable level for satisfaction, sense of success, and sense of acceptability, the factor analysis results and calculated factor loads can confirm this hypothesis. The results of the third hypothesis show that Iran-Khodro's brand can influence on the consumer's behavior through reputation and age, consequently leading to legitimate brand power of Iran-Khodro. As for the rejection of the force hypotheses, it should be uttered that Iran-Khodro's brand in the terms of applicants' view is not rewarding; because the result show that this brand does not have a high acceptability and does not create a distinguished social status. Finally, the confirmation of the fifth hypotheses indicates that the appropriate expert brand power of Iran-Khodro can affect the consumer's behavior through images resulted from expertise and or specialized knowledge, quality, and high performance continuity and superior knowledge of the mentioned brand. In addition to what was mentioned above, as for the agreement of the present research with other researches, it should be noted that the research results of Heidar-Zadeh (2010) agrees with the results of the present research. Qalandari et al (2011) supports parts of the present research. According to the afore-mentioned, the research applied suggestions are as follows:

The present research offers the Iranian auto-making companies to have a powerful brand identifying the operational dimensions of the brand social power bases and take steps to improve the brand social power bases. The full description of these dimensions is depicted in figure (3).

To put the first offer into practice and to enable an effect on the consumer's behavior through creating awareness 
towards the negative outcomes( coercive power) we suggest that the outcomes like sense of failure, sense of being outsider, lack of approval, and inferior impressions of social statues social statues be shown to the customers through advertisement .

In the line of improving the brand social power bases and specially Iran-Khodro's brand model, this company can affect the consumer's behavior through positive images based on this dissatisfaction, sense of success, and acceptability.

In order for Iran-Khodro Company to have a powerful brand, it can apply its reputation and age to express its own legitimate brand in advertisements and commercials. It is due to the factor analysis results of the most effective brand social power bases of Iran-Khodro and its legitimacy based on the brands age and reputation in Iran.

According to the rejection the fourth hypothesis, it is suggested that Iran-Khodro 's brand follow to have creating a higher sense of acceptability and superior social statues. This is possible using and appropriate image of Iran-Khodro.

\section{References}

Arthur Rooney Joseph. (1995)." Branding: a trend for today and Tomorrow", Journal of product \& brand management Vol. 4, No. 4, PP, $48-55$.

Baker, T. L., Hunt, J. B., \& Scribner, L. L. (2002), "The Effect of Introducing a New Brand on Consumer Perceptions of Current: The Roles of Product Knowledge and Involvement", Journal of Marketing Theory\& Practice, Vol 2, № 13, 34 - 45.

Chieranee, Ibrahim, Sabouri, Matin. (2011), a comparison of power of all kinds of internal and external brands from point view of customers, business management, third period, $8^{\text {th }}$ No. $p$ 41-60.

Chaudhuri, A., \& Holbrook, M. B. (2001), "The chain of effects from brand trust and brand affect to brand performance: The role of brand loyalty", Journal of Marketing, Vol 65, № 3, 81-93.

Chen Hsiu-Li. (2007)."Gray marketing and its impacts on brand equity", Journal of product \& brand management, vol. 16, No. 4, PP. $147-256$

Chirani, E., Taleghani, M., \& Esmailie Moghadam, N. (2012), Brand Performance and Brand Equity, Interdisciplinary Journal of Contemporary Research In Business, Vol 3, No 9, 1033-1036.

Douglas E. Hughes \& Michael Ahearne. (2010), Energizing the Reseller's sales force: the power of brand, Journal of Marketing, Vol. 74 (July 2010), 81 - 96

Heydarzade hanzaee, Kambiz, Ghalandari kamal, Noruzi, Abdollah. (2011), The effect of brand social power dimension on purchasing decision based on Iranian costumers, world applied science journal, Vol 13, No 5, 1197-1208

Heidar-Zadeh, Kambiz, Alvani, Seyed Mehdi, Qalandari Kamal. (2010), study of brand social power dimension based on mental preparation levels of customers on purchase decision, management researches, №.86, 27-45

Hassani, Ali, Mousavi Bazargan, Jalal, Qadirinia, Mohammad. (2013), brand performance, conceptualization and measurement, Elm and Farhang quarterly magazine, $8^{\text {th }}$ period, №.3, p 45-64.

Keller, K. L. (2001). "Building customer-based brand equity", Journal of Marketing Management, Vol 10, No, 1,pp 15 - 9.

Katler Philip, Armstrong Gary. (2005) marketing principles", translated by Bahman Fourozandeh, $6^{\text {th }}$ edition, Esfahan.

krosno, J, Freling, H, Skinner, S. (2009), Does brand social power mean might? Phsycology and marketing, Vol 26, № 2, 102 - 124.

Motameni, M., \& Shahrokhi, M. (1998). "Brand Equity Valuation: A Global Perspective", Journal of Product and Brand Management, Vol 7, № 3, pp 275 - 90.

Vergin, R. C., \& Qoronfleh, M. W. (1998), "Corporate reputation and the stock market", Business Horizons, Vol 41, №, 4, pp 19 - 26.

Woon Bong Na, Roger Marshall, Kevin Lane Keller. (1999), Measuring brand power, journal of product \& brand management, VOL. 8 NO, 3, 1999, pp. 170 - 184. 